\title{
OPINION
}

\section{Designing a post-genomics knowledge ecosystem to translate pharmacogenomics into public health action}

\author{
Edward S Dove' ${ }^{1,3}$, Samer A Faraj2, Eugene Kolker ${ }^{4,5,6}$ and Vural Özdemir ${ }^{2,3,6 *}$
}

\begin{abstract}
Translation of pharmacogenomics to public health action is at the epicenter of the life sciences agenda. Post-genomics knowledge is simultaneously coproduced at multiple scales and locales by scientists, crowd-sourcing and biological citizens. The latter are entrepreneurial citizens who are autonomous, self-governing and increasingly conceptualizing themselves in biological terms, ostensibly taking responsibility for their own health, and engaging in patient advocacy and health activism. By studying these heterogeneous 'scientific cultures', we can locate innovative parameters of collective action to move pharmacogenomics to practice (personalized therapeutics). To this end, we reconceptualize knowledge-based innovation as a complex ecosystem comprising 'actors' and 'narrators'. For robust knowledge translation, we require a nested postgenomics technology governance system composed of first-order narrators (for example, social scientists, philosophers, bioethicists) situated at arm's length from innovation actors (for example, pharmacogenomics scientists). Yet, second-order narrators (for example, an independent and possibly crowd-funded think-tank of citizen scholars, marginalized groups and knowledge end-users) are crucial to prevent first-order narrators from gaining excessive power that can be misused in the course of steering innovations. To operate such 'self-calibrating' and nested innovation ecosystems, we introduce the concept of 'wiki-governance' to enable mutual and iterative learning among innovation actors and first- and second-order narrators.
\end{abstract}

\footnotetext{
*Correspondence: vural.ozdemir@mcgill.ca
}

${ }^{2}$ Research Group on Complex Collaboration, Desautels Faculty of Management, McGill University, 1001 Sherbrooke Street West, Montreal, QC, Canada H3A 1 G5 Full list of author information is available at the end of the article
'[A] scientific expert is someone who knows more and more about less and less, until finally knowing (almost) everything about (almost) nothing.' [1] 'Ubuntu: I am because you are.' [2]

Translating genomics: are we connecting the dots? Translation of pharmacogenomics to public health action has been at the epicenter of the life sciences research and development (R\&D) agenda since the completion of the Human Genome Project (HGP) a decade ago. In the current post-HGP ('post-genomics') era, the interconnectedness of biotechnology designers, innovators and consumers of scientific knowledge might appear too obvious a need to mention. After all, why design and innovate a product (for example, a pharmacogenomics test) if it were not to meet the needs of the attendant users? The southern African concept of ubuntu epitomizes the mutual interdependency of human beings, be they scientists or citizens, and the message that 'no person is an island' [2]. One would think the spirit of ubuntu is already well-established among the expert communities that comprise the post-genomics innovation ecosystem.

But experts, by virtue of disciplinary hyperspecialization that is endemic in the post-genomics era, suffer from professional blind spots $[1,3,4]$. Such siloed knowledge is a barrier to putting genomics to action. Nearly a century ago, Thorstein Veblen noted 'trained incapacity', referring to acquired blind spots in professions or 'learned inability' to maintain a collateral vision due to extensive specialist training [4]. Recent studies support Veblen's theory. For example, a scoping analysis of 344 studies in health and allied sciences addressing patients', clinicians' and researchers' priorities for research found that only nine considered the extent to which questions posed by researchers match questions of relevance to patients and clinicians $[5,6]$.

Contributions by Veblen and other scholars [4,7-14] have collectively underscored the risks associated with claiming a 'card-carrying' member status within one's own field or profession, be it public health, pharmacology, 
genetics, industry, government, social science, bioethics or moral philosophy. The risks include an 'echo chamber effect', where one communicates primarily with those who are members of the same disciplinary culture, or think through the same disciplinary lens. This interferes with transdisciplinary synthesis of scientific evidence and can perpetuate or augment the existing knowledge silos in genome medicine $[13,15]$.

Innovation actors operating with vastly different motivations and aspirations, when left unchecked, cannot produce knowledge synchronously at a scale that meets the demands of large-scale post-genomics applications. While one may reasonably argue that synchronous knowledge production in science is not always important (in undirected 'blue sky research', for instance), applied research such as public health pharmacogenomics requires complex collaboration and coordination to generate innovative health products that can be used for population health. One witnesses this in the current global pharmacogenomics research that is materializing in diverse 'scientific cultures' $[3,13,16,17]$. Consistent with this, a scoping study associated with the UK James Lind Alliance report (Tackling Treatment Uncertainties Together) on the broader importance of coordinated R\&D in health sciences has underscored the need for coordination between upstream (research agenda setting) and downstream (implementation and uptake) research: The evidence for informing decisions about health treatments is based largely on research agendas set in an uncoordinated fashion by academics and industry. The launch of the National Health Services (NHS) Research and Development programme, in 1991, instigated a needs-led programme of commissioned research to counterbalance the responsive programmes which rely primarily on researchers suggesting potential research projects to funders. [5]

In addition to professional blind spots in science, previous discussions of genomics have exposed otherwise unchecked and embedded self-interests, whether from academia, government, industry, media or patient advocacy groups, not to mention bioethicists, social scientists and philosophers reflecting on genomics, innovation and society. Scientists and technology-driven expert communities tend to advocate, for example, that 'more research is needed, but policymakers and patient advocacy groups need to act when 'facts are uncertain and stakes are high' (for an excellent overview of the tensions between and opportunities for better cooperation between scientists and policymakers in the face of scientific uncertainties, see the discussion by Bernard Choi et al. [1] and Jerome Ravetz [18]).

Our working premise is that to truly enable a robust public health pharmacogenomics R\&D landscape, postgenomics science warrants a 'third pillar' whereby the political determinants of health are recognized and taken seriously, as much as the social and biological determinants of health [19-23].

This paper introduces, first, the concept and project of 'Mode 2' knowledge production that typifies postgenomics R\&D to a large extent [22,24-27]. It is applied and collective innovation-oriented, and co-produced in multiple scales and at multiple locales, both inside and outside academia. This is contrasted with 'Mode 1' knowledge production, which is narrowly framed, often confined to academia, and has the ethos of 'knowledge for its own sake'. We provide examples of Mode 2 knowledge in pharmacogenomics, such as citizen science, and discuss the implications for post-genomics science. By studying different modes of knowledge production in the post-genomics innovation ecosystem, innovative parameters of collective action can be defined so as to move large-scale data-intensive science such as pharmacogenomics into public health practice.

Second, we discuss knowledge-based innovation as a complex ecosystem composed of innovators ('actors') and regulators ('narrators'). This idea is based on the tenet that one cannot critically examine, in a singularly disinterested manner, the very innovation system in which one is embedded as an innovation actor (for example, a principal investigator conducting a pharmacogenomics project) [21-23]. To achieve robust translation of pharmacogenomics to public health action, we propose a nested post-genomics knowledge governance system composed of first-order narrators (for example, social scientists, philosophers and bioethicists cognizant of technology nuances) situated at arm's length from innovation actors. Yet, second-order narrators (for example, an independent, possibly crowd-funded thinktank alliance of citizen scholars) are also crucial to improve self-calibration and accountability in a postgenomics knowledge ecosystem.

Third, to illustrate knowledge-based innovation as a complex ecosystem, we propose a Web 2.0-driven 'wikigovernance' approach that goes beyond traditional public engagement or citizen participation models to close the gap between research participants and researchers by giving participants and publics the ability to collaborate in pharmacogenomics governance.

\section{'Mode 2' knowledge production and massively collaborative distributed science: letting the 'academic genie' out of the ivory tower?}

Pharmacogenomics is now an old science. With the introduction of genomics science and technology over the past two decades, it has evolved from the predecessor field of pharmacogenetics that has mid-20th century origins in early studies of monogenic variations in drug metabolism. Yet progress in pharmacogenomics science 
is neither driven nor influenced by technology alone. In the current post-genomics era, there have been seismic shifts in the way scientific knowledge is produced. Evidenced by various open science initiatives connected by digital media and Web 2.0, post-genomics knowledge is co-produced in a highly distributed manner. It is extending well beyond the cloistered halls of academia and the laboratory bench space to hitherto unprecedented locales. It impacts, and is being impacted by, new stakeholders such as citizen scientists, developing countries and patient advocacy groups $[3,16,17]$. These stakeholders are contributing, in some cases, to complex scientific tasks [27].

We offer a new perspective that focuses on how scientific knowledge is co-produced in order to understand the emergent forms of collaboration in 'post-genomics pharmacogenomics'. Such a perspective moves us away from codified static knowledge where making information available, transmissible and reproducible across scientific sites was traditionally at the core of the science enterprise. Here, we emphasize the 'knowing' aspect of knowledge production: how is knowledge produced, validated, negotiated, made sense of and enacted in local settings? How is knowledge translated across locations? How does knowledge travel or get translated across organizational boundaries and epistemologies (that is, ways of knowing: how do we know what we know)?

Taking such a dynamic and variegated view of knowledge generation is increasingly important in an age where social media-type technologies enable the emergence of global online communities, support knowledge reuse and remixing, and afford the emergence of generative and massively open forms of collaboration.

Citizen science and crowd-sourcing have recently demonstrated the contributions that can be made by non-professionals (for example, online computer game players) in solving complex scientific problems such as protein structure prediction [28]. Citizen science leverages natural human abilities such as visual pattern recognition or spatial problem-solving skills aided by online computer games. In geographically distributed forms of global science projects such as the Encyclopedia of Life, which documents all living species known to science, non-experts also contribute to data collection in the form of video, sound, images, graphics and text. A recent report on open science released by the UK Royal Society further illustrates the promise of 'massively parallel collaboration' for upstream scientific discovery, study design and research question formulation: Live and open debate played out via wikis and blogs have changed the dynamic of academic discussion - sometimes in extreme ways. In January 2009 Tim Gowers, an eminent mathematician and recipient of the Fields Medal, launched the Polymath Project, a blog serving as an open forum for contributors to work on a complex unsolved mathematical problem. He posed the question: "Is massively collaborative mathematics possible?" He then set out the problem, his ideas about it and an invitation for others to contribute to its solution. 27 people made more than 800 comments, rapidly developing or discarding emerging ideas. In just over a month, the problem was solved. Together they not only solved the core problem, but a harder generalisation of it. In describing this, Gowers said, "It felt like the difference between driving a car and pushing it." [29]

This resonates well with Michael Gibbons and colleagues' concept and project of 'Mode 2' knowledge production [24-27]. Mode 2 knowledge is a simultaneous 'co-production' by a multitude of heterogeneous actors, both experts and non-experts/non-professionals, dispersed in diverse geographical and disciplinary locales and scales. Mode 2, as explained by Barbara Prainsack, is 'where knowledge production takes place inside and outside of organisations and institutions that have ceased to fit within any clear categories' [30].

The concept firmly recognizes the 'social construction' of scientific knowledge and that the boundaries between science, technology and society are highly porous. That is, scientific knowledge is a co-product of technology and natural laws, as well as human values and epistemologies embedded in scientific inquiry. This contrasts sharply with the scientific practices of the original founders of pharmacogenetics in the 1950s, where knowledge was produced within the secluded territory of academia using a 'single-scientist, single-project' model rather than collective innovation and massively collaborative distributed science (Table 1 ).

Mode 2 knowledge production is not without its critics, particularly traditional experts, academics and technologycentered communities who are not necessarily ready to let the 'knowledge production genie' out of the academic ivory tower, that is, from their power domains and controlled territories (for a detailed discussion of this tension in Mode 2 knowledge between scientists and non-expert communities, see the excellent overview by Gibbons et al. [24]). Yet, while there are limits to the extent to which non-experts and non-professionals may contribute to scientific inquiry, it is clear that their role is not relegated to the traditional passive one where they are simply asked to adopt and accept the innovations produced single-handedly by experts [31].

For pharmacogenomics $R \& D$ to be robustly linked to public health action on the ground, we need to recognize that the entire scientific trajectory is open to influences by social systems and human values that remain unchecked in discourses around knowledge-based innovation. The choice and framing of scientific hypotheses, experimental methodology and interpretation of data can 
Table 1. Modes of knowledge production in the post-genomics era

Mode 1 knowledge
Historically prevailed since the origin of modern thought associated with
the Enlightenment and the rise of positivism more than four centuries
ago - accompanied by a firm belief in science as 'special','a thing apart',
'value-neutral'and invariably an objective human activity seeking a
'singular truth'

Produced by experts based on a linear and positivist 'science push' model of innovation

Modus operandi is 'single-scientist single-project'

Assumes that knowledge is value-neutral and is not influenced by human values, politics or social systems in which science is embedded

Envisions a deterministic innovation trajectory once the 'truth' and allegedly objective facts are established

Sites of knowledge production are confined (or cloistered) to academia or expert communities

Uncertainty, if it exists at all, is an accident of science

Narrow peer-review of science, technology and innovation, and primarily by expert communities

Involvement of non-professionals, if permitted, is limited to a discourse on 'product uptake' or 'lack of education of publics'

\section{Mode 2 knowledge}

A recent challenge to knowledge in 'mode $1^{\prime}$ - in recognition that uncertainty and 'unknown unknowns' are ever present in science:

Even the research questions and study designs posed by scientists (not only the outcome and output of science) have unchecked assumptions and embedded value systems at play, that is, science is not a value-neutral or special activity to be placed on an 'untouchable pedestal'

Recognized particularly in scientific fields with vast uncertainties such as global warming, climate change and nanotechnology

'Co-produced' by both experts and non-experts/non-professionals such as citizen scientists, various publics and end-users of scientific innovation;'push-and-pull' model of innovation

Modus operandi is 'massively collaborative open science'

Recognizes the 'social construction' and politics of scientific knowledge and claims made on scientific evidence

Envisions multiple possible (multiplex) future(s) for an innovation trajectory

Citizens or innovation users may have considerations well beyond evidence to adopt an innovation, or may want to take part in the actual production and choice of the evidence on a scientific discovery

Distributed science: geographically and institutionally, with multiple disciplinary lenses

Occurs in institutions or 'locales' that have ceased to fit a classic category as either 'public' or 'private'

Typified by boundary organizations and 'knowledge brokers' between different knowledge communities, whether expert or lay

Recognizes the need to make decisions about science, technology and innovation in the face of uncertainty

Robust 'extended peer review' including experts as well as public engagement and tacit/locally situated knowledge of various innovation actors beyond academia

Non-professionals influence science, technology and innovation at an upstream 'design' or 'research question formulation' stage: that is, in segments of scientific trajectory hitherto cloistered and not permitted to be shaped by non-experts, publics or non-scientists all be influenced by experts' and their institutions' embedded value systems that are not always made explicit [30-33]. Hence, Mode 2 is not a departure from pure knowledge production as such, but an attempt to make the politics of knowledge and the embedded human values and motives transparent and, thus, render knowledge production more robust, actionable and stand the test of extended peer-review by a broader diversity of stakeholders. In a sense, Mode 2 is not new because the boundaries between natural/technical and social systems are highly porous, and have always been (see the excellent autobiographical account on this subject by Brian Wynne [32]). Yet, Mode 2 is novel for offering a coherent explanation for how human values and ways of knowing expressly impact what gets to be produced as scientific knowledge [23].

In opening up the hitherto cloistered halls of academia to a broader range of innovation actors, Mode 2 redistributes power and thus facilitates a more open and collective participation in science. This does not mean that Mode 2 is code for public-private partnerships or 'selling out' science to free markets. It fundamentally moves beyond these artificial binaries and false demarcations between science and society. It highlights the creative potential of intersections and interactions (for example, cooperation, competition, conflict or postcompetitive collaboration) among the innovation actors for a more deliberated, open and robust knowledge production. Helga Nowotny and colleagues observe that: 'Mode 2' is not only a concept, inherently open to manipulation or exploitation by others (even in ways of which we may disapprove); it is also a project, an example of the social distribution of knowledge, which it seeks to describe. ... Closure of the 'Mode 2' debate is neither possible nor desirable. The project has many of the characteristics of the much more open knowledge 
production systems that it is attempting to analyse - wide social distribution, transdisciplinarity, the need for social robustness, and the creative potential of controversies. [26]

\section{Mode $\mathbf{2}$ knowledge and the biological citizen}

As science and knowledge production have become more dispersed with new actors such as citizen scientists or practices such as crowd-sourcing and direct-to-consumer genetic testing, Mode 2 has merged with another emerging post-genomics characteristic: biological citizens. These are entrepreneurial citizens who are autonomous, self-governing and increasingly conceptualizing themselves in biological terms and ostensibly taking responsibility for their own health. Biological citizenship is also accompanied with the rise of patient advocacy and health activism $[34,35]$. Together with opening up previously untouchable domains of scientific enterprise, Mode 2 knowledge symbolizes an ongoing experiment that will be further shaped in ways that are currently unpredictable by the intersections and divergences of technical, social and economic vectors and biological citizenship. Still, one thing is certain: there is much to be gained in reducing research waste [6] by more closely engaging expert communities, non-professionals and end-users through recognition of Mode 2 knowledge production processes and concepts.

\section{Beyond Mode 2: complex collaboration and collective action in the post-genomics innovation ecosystem}

There is a large translation gap in moving genomics technology and basic science discoveries to successful innovation. Muin J Khoury and colleagues [36] found that only $3 \%$ of the US National Institutes of Health (NIH) funding was targeted for downstream translational research. The study did not examine other funding sources or clinical implementation taking place under a variety of mechanisms, including traditional clinical practice, quality and safety initiatives or research. Nonetheless, this finding is important as it points to the small fraction of resources dedicated to translational research compared with basic science [36]. Further investments in translational research and recognition of the role to be played by Mode 2 knowledge in linking basic research to public health practice may remedy this translation gap in genome medicine. The recent NIH initiative to establish the National Center for Advancing Translational Sciences (NCATS) to pursue opportunities for disruptive translational innovation is consistent with Mode 2 genomic knowledge production [37].

While Mode 2 knowledge articulates a new lens to examine and understand post-genomics knowledge production, it does not necessarily embody a 'systems orientation' to innovation. We claim that there is a need to complement and further advance the Mode 2 concept by rethinking post-genomics public health as 'knowledge ecologies' that collectively form an innovation ecosystem. There are compelling reasons why such an ecosystem approach is important for public health pharmacogenomics action on the ground.

First, the multiplicity of actors that enables innovations in the emerging field of public health pharmacogenomics demands coordination and steering capabilities for the entire knowledge ecosystem that underpin and sustain such innovation. Second, it would be naive to assume that innovation actors invariably share complementary or mutually compatible aspirations and aims. Nor can one assume that these motives are immediately made transparent to others. The ethos of advocacy ('change management', or bringing about a change for public health action) is not often cultivated within traditional academic or scientific expert communities, let alone in the course of training as a graduate student in pharmacogenomics. Third, complex collaboration is needed when knowledge crosses organizational, disciplinary or national boundaries, and when actors have differences in research practices and methods, ontologies, human values and epistemologies $[10,11,13]$. Fourth, there is an increasing recognition that knowledge-based post-genomics innovations demand cultivation of ongoing, iterative and mutual learning among the innovation actors so as to enable dynamic and sustainable collective innovation [31].

These considerations together raise collective action problems as well as opportunities to scale up genomics for applications in public health [38]. Traditional modes of knowledge sharing and learning practices among experts, such as annual international meetings and traditional experts-driven peer-review processes, are not always well equipped to translate pharmacogenomics to public action on the ground. Without a steering function, innovations can be stifled or result in redundant research and duplication or waste.

A new theoretical lens is required to conceptualize knowledge-based innovation as a complex ecosystem of 'innovation actors' and 'innovation narrators'. Actors often (and ought to) have self-interests that limit their ability to evaluate the very innovation ecosystem in which they are embedded. On the other hand, it would be naive to place narrators automatically 'above the fray' and think that they will have no self-interests. As with philanthropists, government research funders, academics, industry or the media, first-order narrators also may have self-interests that need to be made explicit. For example, while moral philosophers, bioethicists and social scientists have taken up the task of social critique and study of the social construction of science and technology, their 
normative conclusions (for example, an ethical/unethical technology, person, industry), as with natural scientists, can also be subject to influences by their own value systems and personal career agendas [19,21-23].

One of the unique aspects of the Human Genome Project, in contrast to traditional discipline-bound sciences such as pharmacology, was the intentional funding of research into the attendant ethical, legal and social issues (ELSIs) - a research mandate that continues to the present day in that all research proposals submitted to the US National Human Genome Research Institute must include activities in the ELSI space.

While there is no doubt that these efforts remain crucial, and have moved genomics $R \& D$ increasingly to the Mode 2 knowledge space (relative to pharmacology, for example), there is growing debate within the ELSI community where the next direction(s) should be $[12,39-42]$. It is noteworthy that pharmacogenomics is a 'hybrid' field that draws from both genomics and pharmacology. While genomics now resides within the Mode 2 space, pharmacology as a discipline has lagged behind. For example, pharmacology research does not routinely carry out ELSI research as a contrast to genomics R\&D. Indeed, if we reflect on the panoply of contemporary biomedical disciplines in existence, social pharmacology is 'missing' or kept silent, and sadly does not exist as a formal university department, despite the legitimate recognition of social medicine or social psychiatry in 21st century universities. This is an important gap that is impacting pharmacogenomics as a hybrid science that rests in part on pharmacology scholarship.

As a way forward, a critical examination of how bioethics questions are framed, and the previously unchallenged role of bioethics as an innovation regulator, will be important considerations in planning for translation of pharmacogenomics innovations to public health practice. To this end, it is interesting to note that the myth of bioethics and social science as being inclusive and primarily intended to serve the best interests of publics and marginalized populations, or capturing the broad and real-life issues attendant to pharmacogenomics, quickly dissolves once one steps into a moral philosophy office uninterested in contexts or technology nuances, or a careerist social science laboratory and, thus, observe the more haphazard and messy realities of how 'bioethics-as-regulator' might work in practice. For example, in an analysis of the social and technical expectations surrounding pharmacogenetics and the attendant perceived role of bioethicists as regulators, Adam Hedgecoe has highlighted that: [A]lmost a decade after bioethical debate around pharmacogenetics started, and in contrast to the profession's self-perception as a form of regulator, bioethicists still largely restrict themselves to reviews of possible ethical issues raised by this technology, rather than critiquing others' positions and arguing for specific points of view. ... [B]ioethicists tend to: accept unquestioningly scientists' expectations about the development and ethical issues raised by pharmacogenetics; ignore contributions from bioethicists who do question these expectations; and engage in an ethical debate, the boundaries of which have been laid down and defined by academic and industry scientists. [39].

Hence, second-order narrators (for example, an independent and possibly crowd-funded think-tank alliance of citizen scholars, representatives of hitherto marginalized groups, and knowledge end-users engaged in public scholarship) are crucial [16] to prevent firstorder narrators from gaining undue excessive power that can be potentially abused or incorrectly targeted in the course of steering innovations. Figure 1 illustrates our proposed conceptual model of a post-genomics innovation ecosystem and its elements.

Undoubtedly, the type and range of actors to be included in such an ecosystem are diverse. The examples shown are intended to provide an initial conceptual sample of the possible constituents and their juxtaposition to the innovation narrators of the first and second orders.

In the next section, we introduce a new but related concept: 'wiki-governance.' We situate it within the broader framework of citizen participation in open science so as to concretely define the ways in which the innovation ecosystem constituents, as well as knowledge co-production, can be governed in the spirit of Mode 2 distributed science.

\section{Wiki-governance for knowledge-based innovation ecosystems}

Building on developments in agricultural biotechnology and nanotechnology in the 1990s and 2000s, genomics research has made great strides in incorporating public support to close a perceived 'agency gap' between researchers and research participants and the greater citizenry. This evolution, witnessed in forums such as citizen juries and consensus conferences, is viewed positively in academic circles for substantive, normative and instrumental reasons alike $[42,43]$. It has also been observed empirically that a diversity of publics desires a role in developing science and technology policy, if not merely an offering of general acceptance of a research project or domain $[44,45]$. Models of science and technology public engagement have burgeoned in the past two decades, though to fully understand their underpinnings one must situate them in the larger historical context of social and democratic theory, political science and governance studies. At the same time, a word of 


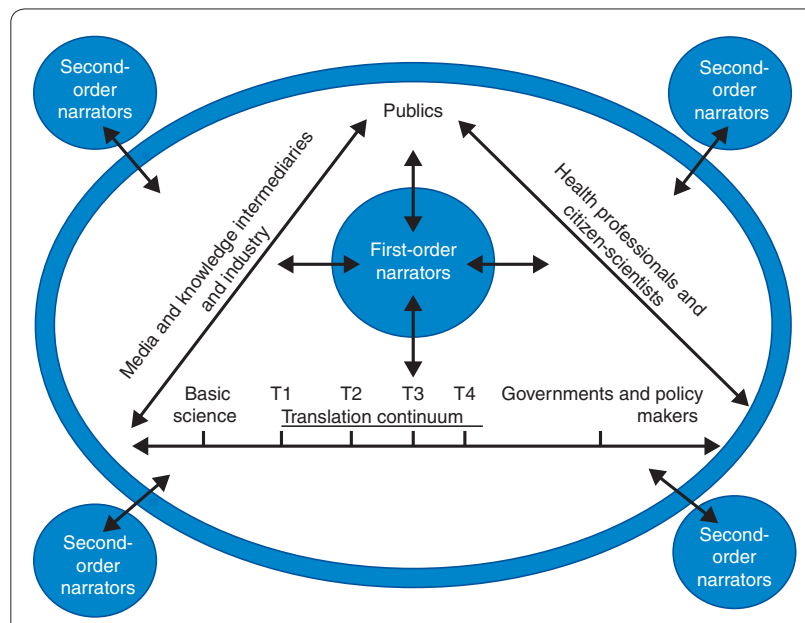

Figure 1. Rethinking knowledge-based innovations as being composed of actors and narrators. In a knowledge ecosystem such as public health pharmacogenomics, innovation actors co-produce knowledge and calibrate their actions and trajectory through open and transparent mutual learning, enabled by recursive practices such as wiki-governance. First-order narrators, who are situated at a crucial but not imperceptible analytical distance from the innovation actors, can examine and steer the innovation ecosystem trajectory, thereby contributing to collective action in the innovation ecosystem. Second-order narrators (for example, innovation observatories represented by citizen scholars, hitherto marginalized groups, and patients) can further keep the first-order narrators in check by making them more accountable, and by rendering visible their actions and situating them in a socio-technical context. Definitions: phase 1 translation (T1) aims to advance a basic genomebased discovery into a candidate health application (for example, a pharmacogenomics test); phase 2 translation (T2) concerns the development of evidence-based guidelines for a pharmacogenomics application; phase 3 translation (T3) aims to connect evidence-based guidelines with health practice, through delivery, dissemination and diffusion research; phase 4 translation (T4) evaluates the real world health outcomes of a pharmacogenomic application. See Khoury et al. [36] for the T1 to T4 translation research continuum and its actors.

caution is necessary: applying 'democracy' to postgenomics R\&D may raise false expectations about binding political norms. The concept of public or citizen 'participation' (or better, 'collaboration'), on the other hand, achieves a more suitable framework for positioning public engagement in post-genomics governance and innovations.

The idea of multiple levels of citizen participation in decision-making can be traced back, at least in modern (and Western) times, to Sherry Arnstein's influential 1969 article on the eight levels of citizen participation, ranging categorically from 'nonparticipation' to 'tokenism' to 'citizen power' [46]. More recently, publicly funded research agencies are engaging in open science as noted above [28], and in the spirit of transparency, state and municipal governments around the world are implementing open data strategies whereby governmentcollected data are distributed online openly so that publics can take the data to either monitor government effectiveness or brainstorm about creating new ways to make public services more user-friendly, more efficient and more interactive.

Many state governments, such as New Zealand, Estonia, Russia and Brazil, are also moving past deliberative democracy to 'participatory democracy', creating 'edemocracy' forums whereby publics can initiate legislative proposals, participate in public hearings, or draft bills - as New Zealand's wiki-drafted Policing Act 2008 demonstrates [47]. Another example of the larger context of public engagement is the concept of 'upstream engagement', seen especially in science and technology fields such as nanotechnology, where publics are included at the embryonic agenda-setting stages of policymaking so as to remedy the epistemic and communicative estrangement between putative experts and lay publics and encourage more dialogue, co-production of knowledge and, ultimately, collaboratively crafted outputs [48].

All of these examples work towards 'empowering' individuals to harness their various skills to achieve collective innovation. However, some models of public engagement, albeit laudable, seem to assume a passively consumptive public that can only digest information unidirectionally disseminated (for example, posting of policies on a website). Other models may involve socalled public 'community members' (for example, townhall-style panels), but in fact may be what Arnstein would label 'placation' and a symbol of tokenism [46] - that is, a facade of inclusiveness that in reality merely acts to legitimate the decisions of science experts.

Indeed, some authors have found that (democratic) deliberation, as the name implies, focuses on inputs without any guarantee of collaborative outputs. Political science analyses indicate that public communication and public consultation resembles more a monologue than dialogue, and even in situations of bidirectional public participation, there is no guarantee of actionable steps beyond processes (for example, gathering diverse viewpoints), especially for the creation of innovative implementable solutions $[49,50]$. Thus, there is a large potential for the greater citizenry to be lulled into a false reassurance of a remedied 'agency gap' or a responsible and representative science and science policymaking agenda. This potential certainly is nestled in the postgenomics field, where so much of the funding comes from taxpayer-endowed public (state) entities, yet experience and expertise increasingly lay with decentered, non-state actors [51]. Loss of public trust and support would be detrimental to post-genomics research in general and would also stall its translation to successful innovations [52].

In light of our proposed innovation and knowledge ecosystem to put public health pharmacogenomics into 
Table 2. Salient differences between previous models of citizen participation and wiki-governance

\begin{tabular}{ll}
\hline Previous models of citizen participation & Wiki-governance \\
\hline Web 1.0 or limited utilization of technology & Web 2.0, social media and network-driven \\
Hierarchical & Non-hierarchical \\
Crowd-sourcing & Structured coordination and role differentiation \\
Procedure-driven deliberation & Solution-driven collaboration \\
Publication of policies for possible comment & Collaborative co-creation of policies \\
Selective reflection of values & Inclusive reflection of multiple values \\
Limited (ongoing) communication channels & Continuous feedback loop \\
Cacophonous and potentially frivolous contributions leading to'tune-out' & Reputational metrics to foster tune-in, good participation practices and trust \\
by innovation actors and failure & of meaningful contributors \\
\hline
\end{tabular}

action, one model that may overcome some of these pitfalls and offer a better avenue for translating pharmacogenomics to public health action is 'wiki-governance', which horizontalizes the traditional decision-making hierarchy and situates itself within a more globally networked and mutuality-driven innovation ecosystem (Table 2) [53,54]. Importantly, wiki-governance grafts the social and political science fields onto the genomics infrastructure by giving publics the ability to shape the innovation trajectory directly and collaboratively. Wikigovernance may be especially useful in biobanks, which are crucial for public health pharmacogenomics. While no biobanks have yet fully adopted the model, several have embraced variations of it, including the reflexive governance approach of the UK Biobank [55] and the adaptive governance approach of the (Canadian) BC Generations Project [56]. Post-genomics R\&D is increasingly conducted with and initiated from biobanks, not only in basic sciences, but also in epidemiology surveillance where large-scale datasets (as in biobanks) can concretely inform R\&D. In biobanks, a full embrace of the model to accelerate the nascent field of public health pharmacogenomics would entail managers and administrators ('biobank builders') developing a secure online forum where publics could register and collaborate in proposing, drafting, commenting on, and amending biobank governance structures, protocols, strategies and policies.

One of the main distinguishing features of wikigovernance is not only its embrace of social media-driven technology, but also the use of structured coordination via issue framing and role differentiation so that individuals can choose the opportunities that best exploit their skills and represent their interests. For example, some individuals may have niche expertise in legal areas such as intellectual property, and thus may want to comment on or draft a biobank policy on commercialization or benefit sharing, whereas other individuals may have a background or interest in genetics or bioethics and decide to focus only on those particular areas. Wikigovernance applications generally do not adhere to a completely libertarian approach. In the example of biobanks, the biobank's management (or similar) committee would act as final arbiters in determining if and when a structure, policy or protocol should be adopted as final, and whether its contents are scientifically, ethically and legally valid. Moreover, the model is flexible in that a continuous feedback loop is employed so that as significant science, technology and socio-legal developments arise, publics can challenge the existing policies and procedures and help anticipate and shape future ones. In sum, wiki-governance expands the innovation actors' collective capacity to imagine and respond to multiple possible (multiplex) future(s) of a given novel innovation trajectory such as public health pharmacogenomics.

Some potential but not insurmountable drawbacks of wiki-governance have been noted elsewhere (for example, scaling and capital investment difficulties, the so-called digital divide, difficulties associated with drafting normative rather than factual policies) [53]. Some have suggested that collaboration with publics will retard rather than accelerate innovations and that lack of putative expertise, consensus on certain values and interests, as well as potential marginalization of certain groups of citizens, could limit the practicality of true public engagement [57]. Yet, a compelling case can be made for the need for pooling diverse knowledge and skills in the backdrop of Web 2.0 and social media technology. As Andy Stirling notes, traditional linear notions of technological progress hide the ways important political choices over alternative directions for innovation are made at every juncture - and should be as subject as other areas of policy, to democratic participation and accountability' [43]. Stirling argues that publics 'can be seen to offer means to reconcile tensions between the otherwise-estranged Enlightenment values of science and democracy' and offer 'an opportunity to be more rigorous about the uncertainties in bioscience innovation and more accountable about the exercise of power' [43].

In post-genomics and related new specialties such as public health pharmacogenomics, where uncertainty is 
paramount and much knowledge remains unknown or indeterminate, models such as wiki-governance can effectively bridge science and democracy to achieve multiple pathways for citizens to rightfully envision themselves as co-creators of genomic science, policy, and successful and sustainable innovation.

\section{Concluding remarks}

Every first order action has second order consequences. With the rise of Mode 2, long-held assumptions of scientists and science are being challenged in the postgenomics era - what it means to be a pharmacogenomics expert or a university professor, whether science and innovation can be singularly entrusted or simply delegated to first-order traditional innovation narrators such as social scientists, philosophers or bioethicists, and whether academia, industry or governments can continue to exclude non-professionals [42]. Indeed, the idea of improving genomics translation for public health action, while important and essential, has hitherto bracketed out the emerging ways in which postgenomics knowledge is co-produced by a multitude of stakeholders.

Increasingly, genomics translation is multi-nodal (multiple stakeholders beyond industry and academia) and multi-modal (multiple ways of knowledge production). Execution of science in the post-genomics era is highly dynamic and extensively distributed, both in terms of geography or 'locales' of knowledge production [58-60] and also in the range of disciplines involved in genomics evidence synthesis [61]. Michael Gibbons notes that there are important choices to be made in universities for the 21st century in reference to knowledge production in Mode 1 and Mode 2: The key questions have less to do with deciding whether a university is to be a research or a teaching institution than deciding between which modes of research - and teaching - to invest scarce resources.... $[\mathrm{T}]$ hese are major questions for any university and their resolution implies even more diversity of institutions than is currently available. [27]

We suggest that these choices are pressuring public health and pharmacogenomics practices outside universities as well, for example, in regulatory agencies, governments, transnational organizations, think-tanks and nongovernmental organizations, and the life sciences, biotechnology and insurance industries. The present analysis of the emerging field of public health pharmacogenomics is an invitation to think outside our own professional habitus and hold judgment upon encounters with new ways of knowledge production. Ultimately, Mode 2 moves us to build the missing third pillar in positivist post-Renaissance science by bringing to the fore the political determinants of health, together with the attendant social and biological determinants.
As we move from a Mode 1 Edisonian science, where data collection and experimental design by a single principal investigator were essential loci of the scientific endeavor, to Mode 2 distributed science, where data collection is automated by next-generation sequencing technologies and increased connectivity among innovation actors, there is an essential need to understand the new ways of doing pharmacogenomics science that enable collective innovation for public health action [13].

\section{Acknowledgements}

The analysis, concepts and work reported herein were supported by the following grants to the authors: a research grant from the Social Sciences and Humanities Research Council (231644) on anticipatory technology governance and OMICS biotechnology foresight (VÖ); Canada Research Chair in Technology, Management \& Healthcare (SAF); the National Science Foundation, Division of Biological Infrastructure award 0969929 (EK), National Institute of Diabetes and Digestive and Kidney Diseases of the National Institutes of Health under awards U01-DK-089571 and U01-DK-072473 (EK), The Robert B McMillen Foundation Award and The Gordon and Betty Moore Foundation (EK).

The present paper was in part prepared during a visit (VÖ) to the Foundation for Genomics and Population Health, Cambridge, UK in June 2012. In addition, insightful and spirited conversations with Nuriye Bilici and Sakine Korkmaz (Cihangir, Istanbul, Turkey), Hesther Tims (Amsterdam, Netherlands), Milu Neves-Pereira (Inverness, UK) and Ron Zimmern (Cambridge, UK) on the concepts of reflexivity and modernity [62] provided the inspiration and helped nuance the discussion in the present paper. The views expressed in this article are the personal opinions of the authors and do not necessarily represent the positions of their affiliated institutions or the funding agencies.

\section{Competing interests}

The authors declare that they have no competing interests.

\section{Abbreviations}

HGP, Human Genome Project; NCATS, National Center for Advancing Translational Sciences; NIH, National Institutes of Health (United States); R\&D, research and development.

\section{Author details}

1 Columbia Law School - LL.M. Program, 435 West 116th Street, New York, NY 10025, USA. ${ }^{2}$ Research Group on Complex Collaboration, Desautels Faculty of Management, McGill University, 1001 Sherbrooke Street West, Montreal, QC, Canada H3A 1G5. ${ }^{3}$ Centre of Genomics and Policy, Department of Human Genetics, Faculty of Medicine, McGill University, 740 Dr. Penfield Avenue, Suite 5200, Montreal, QC, Canada H3A 0G1. ^Bioinformatics \& High-throughput Analysis Laboratory, Seattle Children's Research Institute and Predictive Analytics, Seattle Children's Hospital, 1900 9th Ave, Seattle, WA 98101, USA. ${ }^{5}$ Departments of Biomedical Informatics and Medical Education and Pediatrics, University of Washington School of Medicine, 1959 NE Pacific Street, Seattle, WA 98195, USA. ${ }^{6}$ Data-Enabled Life Sciences Alliance International (DELSA Global), Seattle, WA 98101, USA

Published: 29 November 2012

\section{References}

1. Choi BC, Pang T, Lin V, Puska P, Sherman G, Goddard M, Ackland MJ, Sainsbury P, Stachenko S, Morrison H, Clottey C: Can scientists and policy makers work together? J Epidemiol Community Health 2005, 59:632-637.

2. Tutu D, Tutu M: Made for Goodness: And Why This Makes All the Difference. New York: HarperCollins Publishers; 2010.

3. Özdemir V, Husereau D, Hyland S, Samper S, Salleh MZ: Personalized medicine beyond genomics: new technologies, global health diplomacy and anticipatory governance. Curr Pharmacogenomics Person Med 2009, 7:225-230.

4. Veblen T: The Instinct of Workmanship and the State of the Industrial Arts. New 
York: Macmillan; 1914

5. Oliver S, Gray J: A Bibliography of Research Reports about Patients,' Clinicians' and Researchers'Priorities for New Research. London: James Lind Alliance; 2006.

6. Chalmers I, Glasziou P: Avoidable waste in the production and reporting of research evidence. Lancet 2009, 374:86-89.

7. Society for Social Studies of Science [http://www.4sonline.org/]

8. Bourdieu P: Outline of a Theory of Practice. Cambridge: Cambridge University Press; 1977

9. Bourdieu P, Wacquant L: An Invitation to Reflexive Sociology. Chicago: University of Chicago Press; 1992.

10. Rindova $V$, Yeow A, Martin L, Faraj S: Partnering portfolios, value-creation logics, and growth trajectories: a comparison of Yahoo and Google (19952007). Strategic Entrepreneurship J 2012, 6:133-151.

11. Majchrzak A, More P, Faraj S: Transcending knowledge differences in crossfunctional teams. Organization Sci 2012, 23:951-970.

12. Holmes BJ: A broader perspective on personalized medicine: lessons from discourse analysis and knowledge translation. Curr Pharmacogenomics Person Med 2012, 10:179-181.

13. Faraj S, Kolker E, Bevilacqua L, Özdemir V: Collective theranostics and postgenomics entrepreneurship: Rethinking innovations as knowledge ecosystems built by complex collaboration. Expert Rev Mol Diagn, in press.

14. Dove ES: The genetic privacy carousel: A discourse on proposed genetic privacy bills and the co-evolution of law and science. Curr Pharmacogenomics Person Med 2011, 9:252-263.

15. Özdemir V, Cho WCS: Theranostics: Rethinking post-genomics diagnostics. Expert Rev Mol Diagn, in press.

16. Dandara C, Adebamowo C, de Vries J, Dove ES, Fisher E, Gibbs RA, Hotez PJ, Kickbusch I, Knoppers BM, Masellis M, Oestergaard MZ, Pang T, Rotimi CN: An idea whose time has come? An African foresight observatory on genomics medicine and data-intensive global science. Curr Pharmacogenomics Person Med 2012, 10:7-15.

17. Pang T: Pharmacogenomics and personalized medicine for the developing world - too soon or just-in-time? A personal view from the World Health Organization. Curr Pharmacogenomics Person Med 2009, 7:149-157.

18. Ravetz J: 'Climategate' and the maturing of post-normal science. Futures 2011, 43:149-157.

19. Kickbusch I. Tackling the political determinants of global health. BMJ 2005, 331:246-247.

20. European Commission. EUR 22700 - Science \& Governance - Taking European Knowledge Society Seriously. Luxembourg: Office for Official Publications of the European Communities; 2007.

21. Guston DH, Sarewitz D, Miller C: Scientists not immune to partisanship. Science 2009, 323:582.

22. Özdemir V, Fisher E, Dove ES, Burton H, Wright GE, Masellis M, Warnich L: End of the beginning and public health pharmacogenomics: knowledge in 'Mode 2' and P5 medicine. Curr Pharmacogenomics Person Med 2012, 10:1-6.

23. Dove ES, Özdemir V: 'Regular science' is inherently political. EMBO Rep, in press.

24. Gibbons M, Limoges C, Nowotny H: The New Production of Knowledge. London: Sage; 1994

25. Nowotny H, Scott P, Gibbons M: Re-Thinking Science: Knowledge and the Public in an Age of Uncertainty. Cambridge: Polity Press; 2001.

26. Nowotny $H$, Scott P, Gibbons M: 'Mode 2' revisited: The new production of knowledge. Minerva 2003, 41:179-194.

27. Gibbons M: 1997 Beanland Lecture. What Kind of University? Research and Teaching in the 21st Century. Melbourne: Victoria University of Technology; 1997.

28. Khatib F, Cooper S, Tyka MD, Xu K, Makedon I, Popovic Z, Baker D, Players F: Algorithm discovery by protein folding game players. Proc Natl Acad Sci US A 2011, 108:18949-18953

29. The Royal Society: Science as an Open Enterprise. London; 2012

30. Prainsack B: Book review: Elias G. Carayannis and David F.J. Campbell, Mode 3 Knowledge Production in Quadruple Helix Innovation Systems: 21stCentury Democracy, Innovation, and Entrepreneurship for Development. Minerva 2012, 50:139-142.

31. Özdemir V, Faraj SA, Knoppers BM: Steering vaccinomics innovations with anticipatory governance and participatory foresight. OMICS 2011 , 15:637-646.

32. Wynne B: Daring to imagine

[http://www.india-seminar.com/2009/597/597_brian_wynne.htm]
33. Özdemir V, Knoppers BM: From government to anticipatory governance. Responding to challenges set by emerging technologies and innovation. In Governance for Health in the 21st Century. Edited by Kickbusch I. New York: Springer; in press.

34. Rose N, Novas C: Biological citizenship. In Global Assemblages: Technology, Politics, and Ethics as Anthropological Problems. Edited by Ong A, Collier S. Oxford: Blackwell; 2005:439-463.

35. Tutton R, Prainsack B: Enterprising or altruistic selves? Making up research subjects in genetics research. Sociol Health IIIn 2011, 33:1081-1095.

36. Khoury MJ, Gwinn M, Yoon PW, Dowling N, Moore CA, Bradley L: The continuum of translation research in genomic medicine: how can we accelerate the appropriate integration of human genome discoveries into health care and disease prevention? Genet Med 2007, 9:665-674.

37. Collins FS: Reengineering translational science: the time is right. Sci Trans/ Med 2011, 3:90cm17.

38. Ostrom E: Collective action and the evolution of social norms. J Econ Persp 2000, 14:137-158.

39. Hedgecoe A: Bioethics and the reinforcement of socio-technical expectations. Soc Stud Sci 2010, 40:163-186.

40. Schicktanz S, Schweda M, Wynne B: The ethics of 'public understanding of ethics' - why and how bioethics expertise should include public and patients' voices. Med Health Care Philos 2012, 15:129-139.

41. Özdemir V, Joly Y, Kirby E, Avard D, Knoppers BM: Beyond ELSIs - where to from here? From 'regulating' to anticipating and shaping the innovation trajectory in personalized medicine. In Pharmacogenomics: Challenges and Opportunities in Therapeutic Implementation. Edited by Lam YWF, Cavallari L. Amsterdam: Elsevier, in press.

42. Marris $C$, Rose N: Open engagement: exploring public participation in the biosciences. PLOS Biol 2010, 8:e1000549.

43. Stirling A: Opening up the politics of knowledge and power in bioscience. PLoS Bio/ 2012, 10:e1001233.

44. Dijkstra AM, Gutteling JM, Swart JAA, Wieringa NF, van der Windt HJ, Seydel ER: Public participation in genomics research in the Netherlands: validating a measurement scale. Public Understand Sci 2012, 21:465-477.

45. Lehoux P, Daudelin G, Abelson J: The unbearable lightness of citizens within public deliberation processes. Soc Sci Med 2012, 74:1843-1850

46. Arnstein S: A ladder of citizen participation. J Am Inst Plann 1969, 35:216-224.

47. New York Times Staff: The 7th annual year in ideas. NY Times (Print) 2007, 80 [http://www.nytimes.com]

48. Wilsdon J, Wills R: See-through Science: Why Public Engagement Needs to Move Upstream. London: Demos; 2004

49. Rowe G, Frewer $L$ : A typology of public engagement mechanisms. SciTechnol Human Values 2005, 30:251-290.

50. van der Merwe R, Meehan A: Direct deliberative governance online: consensual problem solving or accommodated pluralism? J Information Technol Politics 2012, 9:46-63.

51. Abbot C: Bridging the gap - non-state actors and the challenges of regulating new technology. J Law Soc 2012, 39:329-358.

52. Kurian P, Wright J: Science, governance, and public participation: An analysis of decision making on genetic modification in Aotearoa/New Zealand. Public Understand Sci 2012, 21:447-464

53. Dove ES, Joly Y, Knoppers BM: Power to the people: a wiki-governance model for biobanks. Genome Biol 2012, 13:158.

54. Noveck BS: Wiki Government: How Technology Can Make Government Better, Democracy Stronger, and Citizens More Powerful. Washington, DC: Brookings Institution Press; 2009.

55. Laurie G: Reflexive governance in biobanking: on the value of policy led approaches and the need to recognise the limits of law. Hum Genet 2011, 130:347-356

56. O'Doherty KC, Burgess MM, Edwards K, Gallagher RP, Hawkins AK, Kaye J, McCaffrey $V$, Winickoff DE: From consent to institutions: designing adaptive governance for genomic biobanks. Soc Sci Med 2011, 73:367-374.

57. Papaioannou T: From consultation to deliberation? A qualitative case study of governing science and technology projects for the public good. Crit Public Health 2012, 22:235-251.

58. Knoppers BM: Genomics and policymaking: from static models to complex systems? Hum Genet 2009 125:375-379.

59. Chalise P, Batzler A, Abo R, Wang L, Fridley BL: Simultaneous analysis of multiple data types in pharmacogenomic studies using weighted sparse canonical correlation analysis. OMICS 2012, 16:363-373. 
Dove et al. Genome Medicine 2012, 4:91

Page 11 of 11

http://genomemedicine.com/content/4/11/91

60. Shanker A: Genome research in the cloud. OMICS 2012, 16:422-428.

61. Veenstra DL, Piper M, Haddow JE, Pauker SG, Klein R, Richards CS, Tunis SR, Djulbegovic B, Marrone M, Lin JS, Berg AO, Calonge N: Improving the efficiency and relevance of evidence-based recommendations in the era of whole-genome sequencing: an EGAPP methods update. Genet Med, in press.

62. Bauman Z: Liquid Modernity. Cambridge, UK: Polity Press; 2000. doi:10.1186/gm392

Cite this article as: Dove ES, et al:: Designing a post-genomics knowledge ecosystem to translate pharmacogenomics into public health action.

Genome Medicine 2012, 4:91. 